Gut, 1989, 30, 50-53

\title{
Smoking delays gastric emptying of solids
}

\author{
G Miller, K R PAlMER, B SMith, C FERRINGTON, AND M V MERRICK \\ From the GI Unit and Department of Radioisotope, Western General Hospital, Edinburgh
}

\begin{abstract}
SUMMARY Oesophageal transit and gastric emptying of liquids and solids was measured in eight normal subjects with a single test meal containing In $^{113}$ labelled water and an omelette labelled with $\mathrm{Tc}^{99 m}$ sulphur colloid. Each volunteer was studied, basally, whilst continuously smoking, and while chewing nicotine gum. Neither liquid, nor solid oesophageal transit were affected by smoking, or gum. Liquid gastric emptying occurred exponentially and clearance was not affected by smoking nor

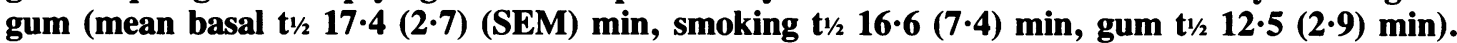
Gastric emptying of solid had three components. An initial mean lag phase increased from $17 \cdot 5(2 \cdot 7)$ $\mathrm{min}$, to $27.5(6 \cdot 1) \mathrm{min}(\mathrm{p}<0 \cdot 05)$ during smoking, but was not prolonged by nicotine gum $(17 \cdot 5(1 \cdot 1)$ min). A subsequent linear emptying phase was also slowed by smoking from a mean of $1 \cdot 01(0 \cdot 15) \%$ min to $0.80(0 \cdot 15) \% \mathrm{~min}(\mathrm{p}<0.05)$, but was not affected by nicotine gum, $1.06(0 \cdot 2) \% \mathrm{~min}$. A third complex phase of solid gastric emptying was not analysed. Smoking delays gastric emptying of solids, but not liquids; nicotine is not responsible for this effect. This observation may partly explain the adverse effect of smoking in patients with gastro-oesophageal reflux.
\end{abstract}

The effects of cigarette smoking upon gastroduodenal secretion are controversial. Smoking has been reported to decrease ${ }^{1}$ and to increase ${ }^{2}$ gastric acid and pepsin secretion. Smoking decreases mean duodenal $\mathrm{pH}$ by inhibiting duodenal mucosal ${ }^{3}$ and pancreatic bicarbonate ${ }^{4}$ secretion. These effects may explain the known adverse effects of smoking upon the natural history of peptic ulcer. ${ }^{5}$ Patients with symptomatic gastro-oesophageal reflux also tend to improve when they stop smoking. The observations that gastro-oesophageal emptying tends to be slow in patients with gastro-oesophageal reflux ${ }^{6}$ and in peptic ulcers, ${ }^{7}$ and that drugs which accelerate gastric emptying improve symptoms, suggest that abnormal oesophagogastric motility may be a relevant factor in these diseases. This has prompted us to assess the effects of smoking upon oesophageal and gastric emptying of liquids and solids. To our knowledge this has not previously been studied in man.

\section{Methods}

SUBJECTS

Eight healthy male volunteers aged $21-58$ years, who regularly smoked $20-40$ cigarettes daily were studied.

Address for correspondence: Dr K R Palmer, Gastrointestinal Unit, Western General Hospital, Crewe Road, Edinburgh EH4 2XU.

Received for publication 15 July 1988.
None had a history of heartburn, chronic indigestion or peptic ulcer. None had undergone abdominal surgery except appendicectomy (three subjects). No subject regularly took medication of any description nor abused alcohol.

EXPERIMENTAL DESIGN

Each subject was studied on three occasions at weekly intervals. On the first occasion at least 12 hours after smoking (basal study), on a second occasion whilst continuously smoking from 30 minutes before the test meal and until gastric emptying was complete, and on a final occasion at least 12 hours after smoking and whilst continuously chewing nicotine gum (4 mg sticks - Nicorette, Lundbeck Ltd, Beds, UK). Each subject therefore acted as his own control.

MEASUREMENT OF OESOPHAGEAL AND GASTRIC EMPTYING

Each subject was studied at 800-900 am after an overnight fast and at least 12 hours after smoking. Oesophageal liquid transit was first measured by assessing the passage of a single swallow of $10 \mathrm{ml}$ water containing $4 \mathrm{mBq}$ of $\operatorname{In}^{113 \mathrm{~m}}$ labelled DPTA. The subject stood facing a large field of view gamma counter fitted with an appropriate high energy 
collinator, attached to a dedicated microcomputer. Data were collected at four frames per second for 60 seconds for liquid swallowing and two frames per second for 120 seconds for the solid swallow. Three areas of interest between the sternal notch and the xiphisternum were identified from the summed image and time activity curves were generated for each.

The time taken for the peak of radioactivity to pass from the upper to the lower area with the patient in the standing position was taken as the liquid transit time. Oesophageal solid transit time was then measured in a similar manner during a single swallow of a portion of omelette which had been labelled with $4 \mathrm{mBq}$ of $\mathrm{Tc}^{99 \mathrm{~m}}$ sulphur colloid. In both cases the subject was instructed to swallow once only. In a preliminary series of experiments adherence of the $\mathrm{Tc}^{99 \mathrm{~m}}$ sulphur colloid to the meal was confirmed by incubating a radiolabelled omelette with gastric juice at $37^{\circ} \mathrm{C}$ for two hours. The mixture was then filtered; less than $2 \%$ of the radioactivity was detected in the filtrate.

After the oesophageal transit study each subject consumed the remainder of the omelette and drank a further $100 \mathrm{ml}$ water. The subject was positioned first facing, then with his back to the camera and an area of interest over the stomach was identified in each projection. A dual counting technique was used to monitor liquid $\left(\mathrm{In}^{113}\right)$ and solid $\left(\mathrm{Tc}^{\mathrm{Y \% m}}\right)$ gastric emptying simultaneously. Pairs of 'frames were obtained every two minutes until solid emptying was complete. Anterior and posterior views were taken to correct for differential attenuation. ${ }^{12}$

Gastric emptying data were analysed by the computer, which produced best fit values for liquid and solid emptying.

Gastric emptying of liquids was best described by a monoexponential model. The time taken, in minutes for half the $\mathrm{In}^{1 \mathrm{~mm}}$ to empty from the stomach, $\mathrm{t} 1 / 2$, was determined. Solid gastric emptying had three components. The first of these was a lag phase during which the solid component did not empty and which was defined as the time, in minutes, taken for the first $5 \%$ of the total $\mathrm{Tc}^{9 \%}$ radioactivity to leave the stomach. This was followed by a linear emptying phase which was present until the majority of the $\mathrm{Tc}^{9 \% \mathrm{~m}}$ had left the stomach. It was expressed as percentage of total radioactivity $/ \mathrm{min}(\% / \mathrm{min})$, between $95-45 \%$ of emptying. A final exponential phase was not analysed (Fig. 1).

\section{STATISTICAL ANALYSIS}

Liquid phase emptying was fitted to a single exponential function; solid phase (after the lag period) to a linear function. Differences between groups were analysed using the Wilcoxon's rank test.

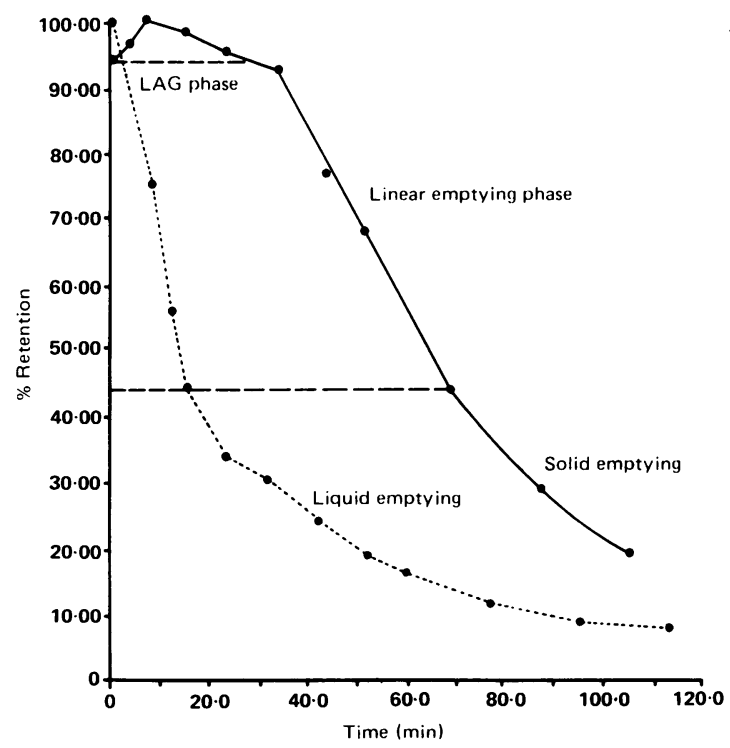

Fig. 1 Example of a gastric emptying study illustrating the analysis of the liquid and solid phases.

\section{Results}

The number of cigarettes smoked during the smoking phase of the experiment ranged from $2 \cdot 1$ to $5 \cdot 3$ /hour (median 3.5). All subjects apparently inhaled the cigarette smoke; each cigarette yielded 14-20 puffs and lasted 7-14 minutes (median $10 \mathrm{~min}$ ). The amount of gum chewed by each subject in the last phase of the experiment ranged from 6-12 mg/hour (median $9 \mathrm{ng} / \mathrm{h}$ ). Consumption was limited by the development of headaches.

The results of oesophageal and gastric emptying studies are shown in the Table. Oesophageal transit times for liquids and solids were not affected by smoking or gum. It was not always possible to measure the transit of the solid component because

Table Summary of oesophageal and gastric emptying

\begin{tabular}{lccc}
\hline & \multicolumn{3}{c}{ Study period-mean (SEM) } \\
\cline { 2 - 5 } & Basal & Smoking & Gum \\
\hline $\begin{array}{l}\text { Liquid oesophageal transit } \\
(\text { sec) }\end{array}$ & $1 \cdot 6(0 \cdot 2)$ & $2 \cdot 1(0 \cdot 6)$ & $1 \cdot 6(0 \cdot 2)$ \\
$\begin{array}{l}\text { Solid oesophageal transit } \\
(\text { sec) }\end{array}$ & $6 \cdot 7(0 \cdot 8)$ & $5(0 \cdot 7)$ & $4 \cdot 4(0 \cdot 7)$ \\
$\begin{array}{l}\text { Liquid emptying t } 1 / 2 \\
\text { Solid emptying lag phase } \\
(\text { min) }\end{array}$ & $17 \cdot 1(2 \cdot 7)$ & $16 \cdot 9(7 \cdot 4)$ & $12 \cdot 5(2 \cdot 9)$ \\
$\begin{array}{l}\text { Solid emptying linear phase } \\
(\% \text { min) }\end{array}$ & $1 \cdot 01(0 \cdot 15)$ & $0 \cdot 80(0 \cdot 15)^{*}$ & $1 \cdot 06(0 \cdot 2)$ \\
\hline
\end{tabular}

${ }^{*} \mathrm{p}<0 \cdot 05$, smoking $v$ basal and gum periods. 


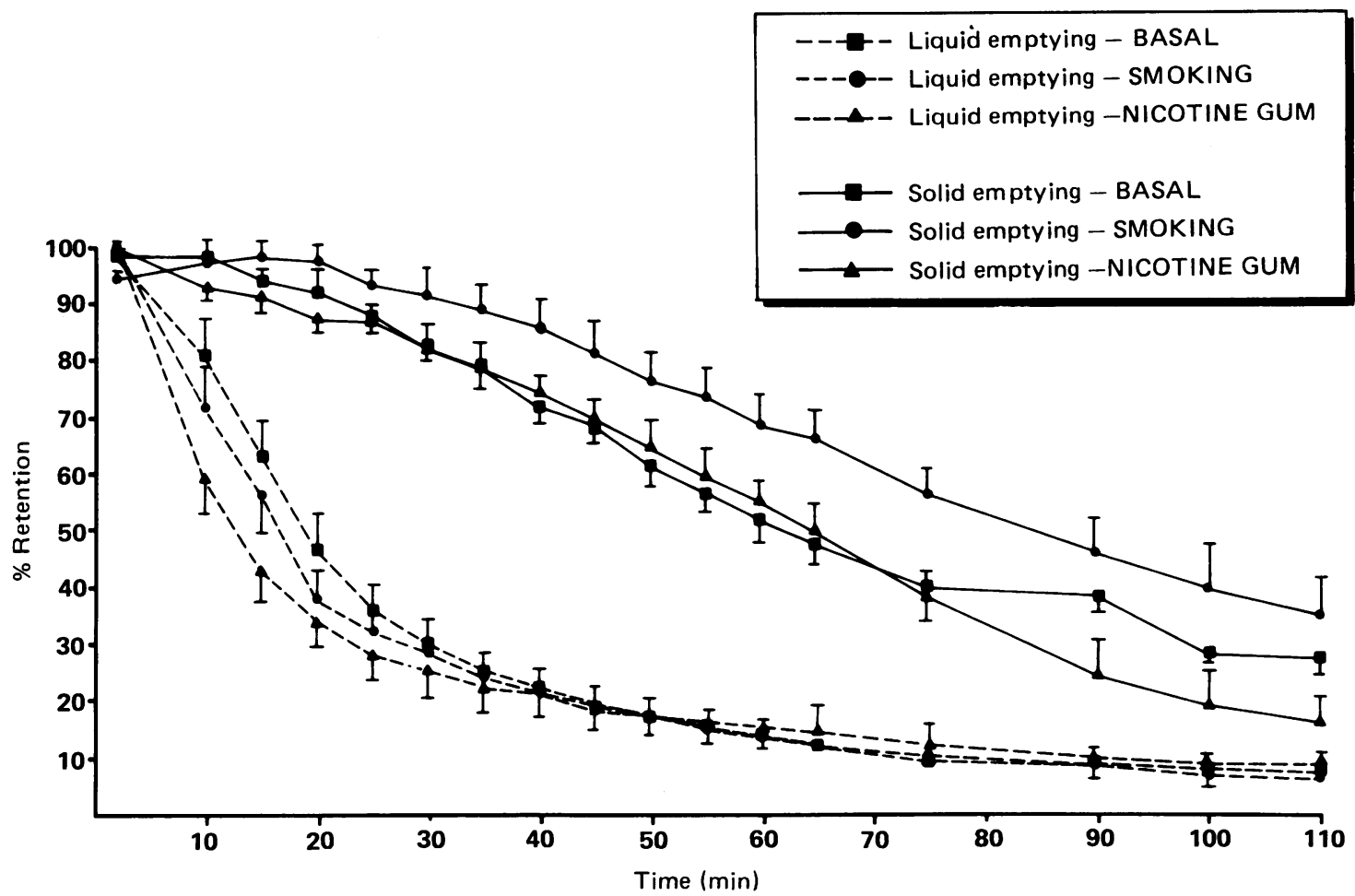

Fig. 2 Mean gastric emptying data for liquid and solid components of the mean under basal conditions, whilst smoking and whilst chewing nicotine gum.

the peak of radioactivity at the xiphisternum was sometimes ill defined. This may have been because of repetitive swallows or interference from the previous liquid swallow. The range of values for oesophageal transit was wider than that of liquids and reproducibility appeared poor. There was no correlation between values for liquid and solid emptying.

Gastric emptying $t 1 / 2$ for liquids was similar under basal conditions, whilst smoking and whilst chewing gum (Fig. 2). In contrast, both components of solid gastric emptying were affected by smoking but not gum. The mean duration of the lag phase increased and the mean linear emptying component rate decreased during smoking $(p<0 \cdot 05)$, but these were not affected by gum.

There was no relationship between oesophageal transit time for liquids or solids and the values for liquid or solid gastric emptying. This was true under basal conditions, during smoking and whilst chewing gum.

\section{Discussion}

The radioisotope techniques used in this study allowed us to simultaneously measure oesophageal and gastric emptying of liquids and solids. It is perhaps not surprising that there were no apparent relationships between these four aspects of upper gastrointestinal motility in normal subjects. Nevertheless this method may be of value in relating oesophageal and gastric emptying in disease states, after vagotomy and during drug therapy. Very frequent measurement of radioactivity during gastric emptying very clearly showed the three components of solid transit. We believe that the initial lag period represents the phase of solid liquifaction, the 'antral mill' which is determined by a gastric pacemaker ${ }^{8}$ and influenced by neural ${ }^{9}$ and humeral factors. ${ }^{10}$ The subsequent linear emptying phase almost certainly represents efflux of uniform boluses of the homogenate and is dependent upon the pressure difference between the stomach and duodenum. "In contrast the exponential emptying of liquids suggests that this is a predominantly passive process.

A problem associated with gastric emptying studies is that of reproducibility. Values for gastric emptying widely differ between subjects and may change in the same individual from one day to 
another in response to emotional or physical stress in addition to disease states. ${ }^{12}$ In order to try and minimise this problem each subject acted as his own control and was studied under identical conditions at the same time of day within a relative short time period. The observation that basal values were similar to those obtained whilst chewing gum suggests that the problem of reproducibility may have been overcome. The mechanism by which smoking delays gastric emptying of solids but does not affect liquid emptying kinetics has not been definitely established. The differences in the mathematical function describing solid emptying provide a clue. We suggest that the gastric pacemaker which controls solid emptying is affected, either by neural or humeral factors or by changes in prostaglandin metabolism. It appears unlikely that the effects of smoking upon gastric emptying are mediated by nicotine. Serum nicotine concentrations were not measured. Others have demonstrated similar values during smoking and chewing nicotine gum although blood concentrations rise more slowly after chewing gum. ${ }^{13}$ One feature of gastro-oesophageal reflux disease is delayed gastric emptying of solids with relatively normal liquid emptying. ${ }^{3}$ Although our study involved normal subjects who had no history of heartburn, our findings do suggest a mechanism which could account for the clinical observation that symptoms are exacerbated by smoking.

\section{References}

1 Konturek SJ, Solomon TE, NcWeight WG, et al. Effects of nicotine on gastro-intestinal secretions. Gastroenterology 1971; 61: 1098-105.
2 Murthy SNS, Dinosa VP, Clearfield HR, et al. Simultaneous measurements of basal pancreatic, gastric acid secretion, serum gastrin and secretin during smoking. Gastroenterology 1977; 73: 758-61.

3 Murthy SNS, Dinosa VP, Harris R, et al. Senal pH changes in the duodenal bulb during smoking. Gastroenterology 1978; 75: 1-4.

4 Bochonek WJ, Koronczewski R. Effect of cigarette smoking on bicarbonate and volume of duodenal contents. Am J Dig Dis 1973; 18: 729-33.

5 Harrison AR, Elashoff JD, Grossman MI. Smoking and health. A report to the Surgeon General. Washington: DHEW Publication No. 79-50066, 3-21, 1976.

6 McCallum RW, Mensh R, Lange R. Definition of the gastric emptying abnormality present in gastrooesophageal reflux patients. Gastroenterology 1981; 80: 1226.

7 Miller LJ, Malagelada JR, Longstreth GF, et al. Dysfunction of the stomach with gastric ulceration. Dig Dis Sci 1980; 25: 857-64.

8 Code CF, Szurszewski JH, Kelly KA, et al. A concept of control of gastrointestinal motility. In: Code CF, Heidel $\mathrm{H}$, eds. Handbook of physiology: The alimentary canal Vol 5. Baltimore: Williams and Wilkins, 1968: 288-91.

9 Marik F, Code CF. Control of the interdigestive myoelectric activity in dogs by the vagus nerves and pentagastrin. Gastroenterology 1975; 69: 387-95.

10 Strunz UT, Code CF, Grossman MI. Effects of gastrin on electrical activity of antrum and duodenum of dogs. Proc Soc Exp Biol Med 1979; 161: 25-7.

11 Minami H, McCallum RW. The physiology and pathophysiology of gastric emptying in humans. Gastroenterology 1984; 86: 1592-610.

12 Tothill P, McLouglin GP, Heading RC. Techniques and errors in scintigraphic measurements of gastric emptying. J Nucl Med 1978; 19: 256-61.

13 Russel MAH, Feyerabend C, Cole PV. Plasma nicotine levels after cigarette smoking and chewing. $\mathrm{Br}$ Med J 1976; i: $1043-6$. 